\title{
Dynamic Feedback Control And State Observers For A Knee Rehabilitation Device Using Soft Action
}

\author{
Andrés Felipe Guatibonza Artunduaga ${ }^{1}$ \\ LEONARDo ENRIQUE SOLAQUe GUZMÁN ${ }^{1}$ \\ $\checkmark$ ALEXANDRA VELASCO VIVAS ${ }^{1}$
}

\section{Abstract}

Rehabilitation devices with soft components increasingly attract more attention due to their characteristics in human-robot interaction. However, these types of systems have a certain level of complexity when analyzing and controlling. We have designed a 5-link knee rehabilitation device operated on two of the five joints using elastic action to help the movement of the knee. In this work, we simplify the modeling of the rehabilitation device in a smooth acting system of 1 degree of freedom. Subsequently, we present the design and implementation of a dynamic feedback controller to track a desired reference. For the proposed controller, we implemented a state observer to estimate the rigidity of the system and some of the states. As a result, we present the design and implementation of the controller with a status observer, which follows a desired angular path with a desired stiffness. We demonstrate in simulation, through tests aimed at carrying out some rehabilitation routines, to validate the effectiveness and stability of the controlled system, which responds effectively to disturbances.

Keywords: Assistive Robotics, Rehabilitation Robotics, Kinematics Modeling, Dynamics Modeling.

\section{Control por retroalimentación dinámica y observadores de estado para un dispositivo de rehabilitación de rodilla usando actuación flexible}

\section{Resumen}

Los dispositivos de rehabilitación con componentes flexibles cada vez acaparan más la atención debido a sus características en la interacción humano-robot. Sin embargo, este tipo de sistemas tienen cier to nivel de complejidad cuando se realiza el análisis y control. Hemos diseñado un dispositivo de rehabilitación de rodilla de 5 enlaces actuado en dos de las

1 Militar Nueva Granada University, Bogotá, Colombia.

Autor de correspondencia: Velasco Vivas, A. (Alexandra): Carrera 11 N. 101-80,Bogotá, Colombia. Teléfono: oficina: (+57) 1 - 650 0000, Ext. 1280. Correo electónico: alexandra. velasco@unimilitar.edu.co
Historia del artículo:

Artículo recibido: 08-XI-2019/ Aprobado: 15-I-2020

Disponible online: 24 de abril de 2020

Discusión abierta hasta septiembre de 2021 
cinco articulaciones utilizando actuación elástica para ayudar al movimiento de la rodilla. En este trabajo, simplificamos el modelado del dispositivo de rehabilitación en un sistema de actuación suave de 1 grado de libertad. Posteriormente, presentamos el diseño e implementación de un controlador de retroalimentación dinámica para rastrear una referencia deseada. Para el controlador propuesto, implementamos un observador de estados para realizar una estimación de la rigidez del sistema y algunos de los estados. Como resultado, presentamos el diseño y la implementación del controlador con un observador de estado, que sigue una trayectoria angular deseada con una rigidez deseada. Demostramos en simulación, mediante pruebas orientadas a llevar a cabo algunas rutinas de rehabilitación, para validar la efectividad y la estabilidad del sistema controlado, que responde eficazmente a perturbaciones.

Palabras clave: Robótica de Asistencia, Robótica de Rehabilitación, Modelado Cinemático, Modelado Dinámico.

\section{Controle de feedback dinâmico e observadores de estado para um dispositivo de reabilitação de joelho usando ação soft}

\section{Resumo}

Os dispositivos de reabilitação com componentes macios atraem cada vez mais atenção devido às suas características na interação humano-robô. No entanto, esses tipos de sistemas têm um certo nível de complexidade ao analisar e controlar. Projetamos um dispositivo de reabilitação de joelho de 5 elos, operado em duas das cinco articulações, usando ação elástica para ajudar no movimento do joelho. Neste trabalho, simplificamos a modelagem do dispositivo de reabilitação em um sistema de ação suave de 1 grau de liberdade. Posteriormente, apresentamos o design e a implementação de um controlador de feedback dinâmico para rastrear uma referência desejada. Para o controlador proposto, implementamos um observador de estado para estimar a rigidez do sistema e alguns dos estados. Como resultado, apresentamos o projeto e a implementação do controlador com um observador de status, que segue um caminho angular desejado com uma rigidez desejada. Demonstramos em simulação, através de testes destinados a realizar algumas rotinas de reabilitação, para validar a eficácia e a estabilidade do sistema controlado, que responde efetivamente a distúrbios.

Palavras-chave: Robótica Assistiva, Robótica de Reabilitação, Modelagem Cinemática, Modelagem Dinâmica.

\section{Introduction}

The assistive Medicine field represents an area of great application for control systems due to robothuman interaction. Robotics focused on medicine fundamentally associate the information of physical activity that allows the significant improvement of the human ability to perform important tasks, such as rehabilitation therapies or support for people with disabilities in activities of daily life.

Recently, most of the research in physical and robotic rehabilitation therapy is focused on the ability to recover the motion of people who have suffered CVA (Cerebrovascular accident) or traumatic events, Koller-Hodac et al. (2010), Huo et al. (2016). In recent years several robotic systems have been designed for rehabilitation, where efficiency has been proven through various clinical studies, Umivale (2011). The vast majority of the advances achieved, involve the recovery of mobility in the upper and lower limbs. Currently, several technologies that involve the use of soft action are used in the medical and rehabilitation fields. There are robotic assistive devices for physiotherapy of Biomedical Imaging \& Bioengineering (n.d.) of the hip, knee or ankle, as well as for cases involving full-body assistance, such as exoskeletons, Expo (n.d.).

In the case of the lower extremities, these are more likely to be injured. Therefore, much attention has been given to knee rehabilitation. However, there is also an incidence of upper limb injuries. In the literature, we find devices developed for the rehabilitation of upper limbs where elastic elements 
are involved, such as in Lessard et al. (2018), Guo et al. (2015) or Wu et al. (2018). With the idea of having more natural motions that prevent harm to the patient, soft actuation and flexible structures have been used for upper and lower limb rehabilitation, Polytechnique fédérale de Lausanne (n.d.).

For instance, Ma et al. (2016) present a traditional rehabilitation robot design, where a flexible joint to overcome the effect on the stability of the impact load on the rehabilitation robot system is proposed. Similar works, as Lemerle et al. (2017) propose a new design of a finger exoskeleton for rehabilitation with a soft actuator that uses a wire mechanism to rehabilitate patients after neurological trauma has been integrated. Similarly, Erwin \&O’Malley (2017) analyze joint properties, such as passive stiffness and range of motion(ROM) for wrist mobility recovery. In the same context, the work developed by Parivash \& Bamdad (2015) proposes an elbow rehabilitation robot with a novel, cable-based series elastic actuator that allows adjustment of the drive torque and joint stiffness, to provide proper elbow stiffness during the flexionextension movements. Other examples of devices that provide assisted motions are presented for example in Jujjavarapu \& Esfahani (2019), where a method to vary the stiffness of the endpoint using a variable impedance mechanism, using permanent magnets that seeks to reduce the interference of the stiffness in the human final effector is proposed.

We have developed a 5 -link knee rehabilitation device actuated in two of the five joints. We use elastic actuation to help the motion at the knee joint, to produce more natural movements and to prevent further harm to the patient. A complete analysis of our knee rehabilitation device is presented by Guatibonza et al. (2018). The proposed system allows performing knee rehabilitation routines where the normal range of motion should not be exceeded. Besides, the angular velocity decreases when the angular position of the knee approaches the reference. Taking into account soft actuation, there is a relationship between the angular position of the knee and the stiffness of the knee that can be preserved. To comply with these specifications a control strategy is required.

In previous studies, some control strategies were proposed where the results were limited to simulations only. In this document, we present the design and implementation of a dynamic feedback strategy to track the desired reference, for a one-DoF action system, based on Della-Santina et al. (2017) and Solaque \&Velasco (2019). We use a one-DoF manipulator to get an idea of the behavior of the controlled system so that we can then implement the controller in our rehabilitation device. Also, for the proposed controller we require an estimate of the rigidity of the system and other states, so we propose a state observer as part of the design.

Several estimation methods have been already presented with control purposes and also for parameter estimation (see e.g. Allen et al. (2017), Luo et al. (2017), Brahmi et al. (2018)). Estimators allow quantifying nonmeasurable variables, so they are indeed used in control applications for rehabilitation devices. For example, Luo et al. (2017) where an adaptive impedance controller for upper limb rehabilitation robots is presented based on the estimation of stiffness and cushioning of patients using the least-squares method. Similarly, other state observers can estimate model parameters. Such is the case of the one presented in Htoon et al. (2016) where a mathematical model is developed to estimate the mechanical impedance of the upper limb using the least-squares method. Moreover, Brahmi et al. (2018) present an integrated recoil approach with time delay estimation to provide an accurate estimate of unknown dynamics and to compensate external disturbances of a 7-DOF exoskeleton robot.

In this document, we design and implement a dynamic feed-back control and state observer for a knee rehabilitation device using soft actuation. This system allows performing rehabilitation routines that follow a desired joint trajectory with the desired stiffness. We demonstrate in simulation the effectiveness and stability of the controlled system. We show that it behaves effectively in the presence of disturbances. Several tests were performed and are oriented to carry out rehabilitation routines in order to obtain smoother movements with a stiffness approach similar to that of a patient in a common rehabilitation procedure.

In section II we give a detailed description of the system dynamic model and the controller and state observer design. Then, in section III, we explain the system setup for the controller implementation. Afterward, in section IV we report the tests carried out using the physical system and we discuss the results. 


\section{System Formulation}

Consider the expressions that follows a linear approach for a one-DoF system as shown in Figure 1, the linear dynamic approach of the system with soft actuation can be written as:

$$
\left\{\begin{array}{l}
M \ddot{q}+\beta_{q} \dot{q}+k(q-\theta) \\
\ddot{\theta}+\beta_{\theta} \dot{\theta}+k_{\theta} \theta=k_{\tau} \tau_{i n} \\
\ddot{k}+\beta_{k} \dot{k}+k_{k} k=k_{k} v_{i n}
\end{array}\right.
$$

This system actually is a $2 \mathrm{n}$ dimension system due to the elastic component. In (1) $q$ is the link angular position, $\theta$ is the joint angular position, $k$ is the joint stiffness, $M$ is the robot link inertia, $\tau_{i n}$ is the input torque, $v_{i n}$ is the input voltage, $\beta_{\theta}$ and $k_{\theta}$ are electric coefficients, $\beta_{q}$ is the viscous friction coefficient between the rotor and the link, $\beta_{k}, k_{k}$ and $k_{\tau}$ are scaling constants obtained experimentally, which contain the required units.

To obtain the dynamic behavior of the system, it is necessary to implement a state observer (Luenberger) that allows us to estimate the non-measurable variables of the system, so for future purposes it can be analyzed. The observer allows taking relevant actions regarding dynamic control, Luenberger (1971), Ogata (2010). First, we express the equations in a $6 \times 6$ extended matrix form. Rewriting the model, we have:

$$
\left[\begin{array}{c}
\ddot{q} \\
\ddot{k}
\end{array}\right]=\left[\begin{array}{cc}
\sigma_{1} & 0 \\
0 & \sigma_{2}
\end{array}\right]+\left[\begin{array}{cc}
0 & 0 \\
0 & 0 \\
0 & 0 \\
k_{\tau} k / M & 0 \\
0 & 0 \\
0 & k_{k}
\end{array}\right]\left[\begin{array}{l}
\tau_{i n} \\
v_{i n}
\end{array}\right]
$$

Where the model parameters $\sigma_{1}$ and $\sigma_{2}$ correspond the states of $q$ and $k$,

$$
\begin{gathered}
\sigma_{1}=\left[\begin{array}{ccccc}
0 & 1 & 0 & 0 \\
& 0 & 0 & 1 & 0 \\
0 & 0 & 0 & 1 \\
-\frac{k k_{\theta}}{M} & \frac{-\left(\beta_{\theta} k+\beta_{\theta} k_{\theta}\right)}{M} & \frac{-\left(k+M k_{\theta}+\beta_{q} \beta_{\theta}\right)}{M} & \frac{-\left(\beta_{q}+\beta_{\theta} M\right)}{M}
\end{array}\right] \\
\text { and } \sigma_{2}=\left[\begin{array}{cc}
1 & 0 \\
-k_{k} & -\beta_{k}
\end{array}\right]
\end{gathered}
$$

Then, we can define the state space system matrices $A, B, C$ as:

$$
\begin{gathered}
A=\left[\begin{array}{cc}
\sigma_{1} & 0 \\
0 & \sigma_{2}
\end{array}\right], \quad B=\left[\begin{array}{cc}
0 & 0 \\
0 & 0 \\
0 & 0 \\
k_{\tau} k / M & 0 \\
0 & 0 \\
0 & k_{k}
\end{array}\right], \\
C=\left[\begin{array}{llllll}
1 & 0 & 0 & 0 & 0 & 0 \\
0 & 0 & 0 & 0 & 1 & 0
\end{array}\right]
\end{gathered}
$$

\section{Figure 1. Simplified Model Representation}
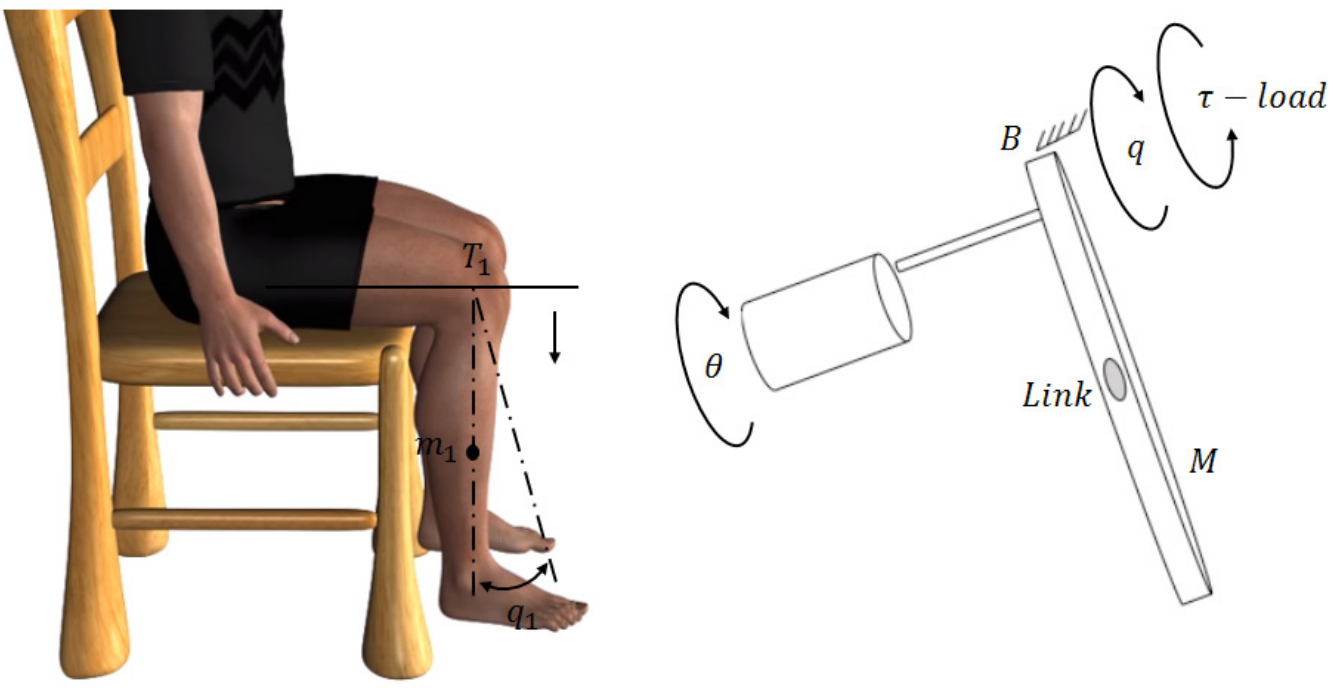
Figure 2. Block Diagram of the Proposed System

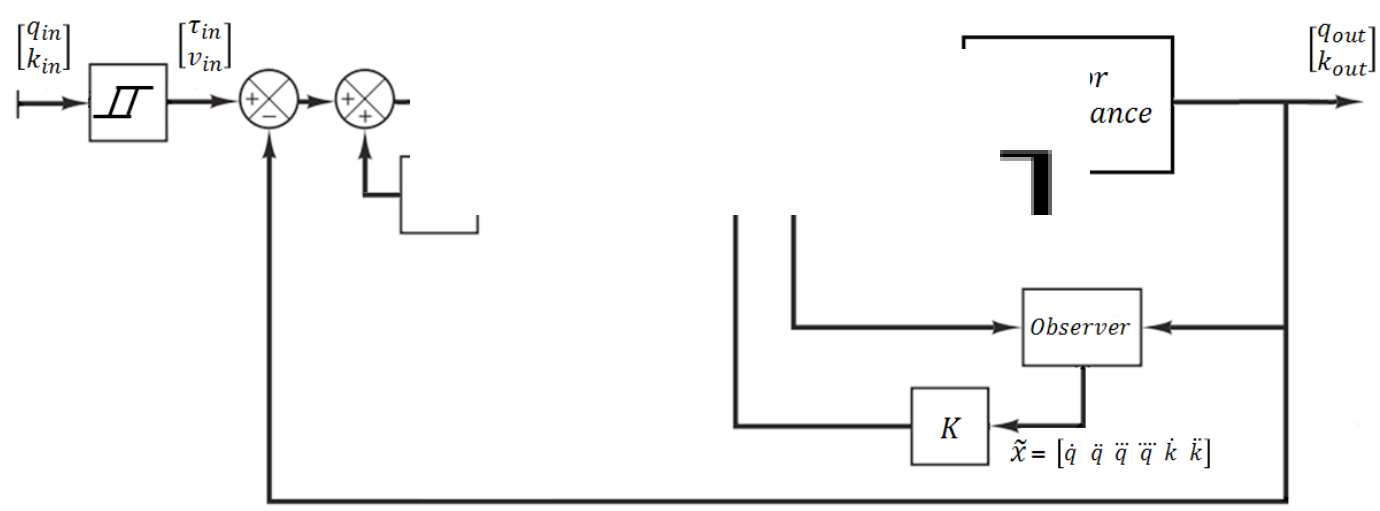

Let us define the output control variables as a vector $y=[q, k]^{\mathrm{T}}$ collecting the link position $q$ and the stiffness $k$. Besides, the control inputs are $u=\left[\tau_{i n}, v_{i n}\right]^{\mathrm{T}}$. The states of the system are $x=(\dot{q}, \ddot{q}, \dddot{q}, \ddot{q}, \dot{k}, \ddot{k})$. A sampling time $T$ is defined to calculate the discrete matrices for $A(s)=G(T), B(s)=H(T)$ and $C(s)=C(T)$. Figure 2, shows the block diagram of the system, including the inputs, outputs, states and system structure.

\section{Controller Design Criteria}

Based on the controllability criteria for the design of control systems in the state space, we establish whether the system is controllable, and then we obtain the controller parameters, Ogata (1996), Ogata (2010). Let us consider a discrete system in space state defined as:

$$
\begin{gathered}
x(T+1)=G x(T)+H u(T) \\
y(T)=C x(T)
\end{gathered}
$$

and the control law given by:

$$
u(T)=-K x(T)
$$

Where $x(T)$ is the $T^{\text {th }}$ state vector, $u(T)$ is the $T^{t h}$ input vector, $y(T)$ is the $T^{\text {th }}$ output vector and $u(T)$ is the $T^{\text {th }}$ controlled variables vector.

Then, using conventional design methods for state space systems, the design of the controller is carried out by assigning poles in order to obtain the proportional control constant $K$ and the integral constant $K_{i}$. These constants are calculated using the extended matrices $\hat{G}$ and $\hat{H}$ Ogata (1996).

$$
\hat{G}=\left[\begin{array}{cc}
G & 0 \\
C G & 1
\end{array}\right], \widehat{H}=\left[\begin{array}{c}
H \\
C H
\end{array}\right]
$$

The poles are located using the Matlab function place to obtain a desired response of the system. Then the constants of the controller and are obtained.

\section{State Observer Design Criteria - Luenberger}

The Luenberger type observer is designed for linear systems with discrete measurements, Luenberger (1971), Ogata (1996). First, we define whether the system is observable based on the observability criteria in state space Ogata (2010). The estimator is given by

$$
\hat{x}(T+1)=G \hat{x}(T)+H u(T)+K e\left(y_{T}-\hat{y_{T}}\right)
$$

Where $\hat{x}(T)$ is the $T^{\text {th }}$ estimated state vector; $\hat{y}(T)$ is the $T^{\text {th }}$ estimated output vector; $y(T)$ is the $T^{\text {th }}$ measured output vector; and $K_{e}$ is the $T^{\text {th }}$ is discretized observer gain matrix.

Then, to determine the feedback gain matrix of the observer, the Ackermann formula is used considering the fully observable system Ogata (1996), and using the desired characteristic polynomial of the error dynamics $\phi(G)$, which can be written as

$$
\phi(G)=G^{n}+\alpha_{1} G^{\mathrm{n}-1}+\cdots+\alpha_{n-1} G+\alpha_{n} I
$$

It is worth to remark that estimated the states of this system are important to monitor the variables that affect the behavior of the outputs through the control strategies applied. Physically, it is not possible to measure the stiffness of the system, so the estimation of the states gives us an important approximation value of the real stiffness. Considering that this is a coupled MIMO system (2n), variables that affect the dynamics of 
the system must be considered since changes in an input affect their respective output and also other outputs.

\section{System Setup}

To carry out a control strategy as the one proposed in this paper, we use a One-Link Manipulator actuated by a Variable Stiffness Actuator (VSA), namely QB advanced of qbrobotics $\AA$, as shown in Figure 3. For the implementation, the proportional control constant, the integral constant, and the observer constant were obtained, which together with the discrete matrices of the system are used to calculate the implementation algorithms from the control expressions with full order status feedback.

Figure 3. QB Advanced Variable Stiffness Actuator with Rigid Link and Main Characteristics

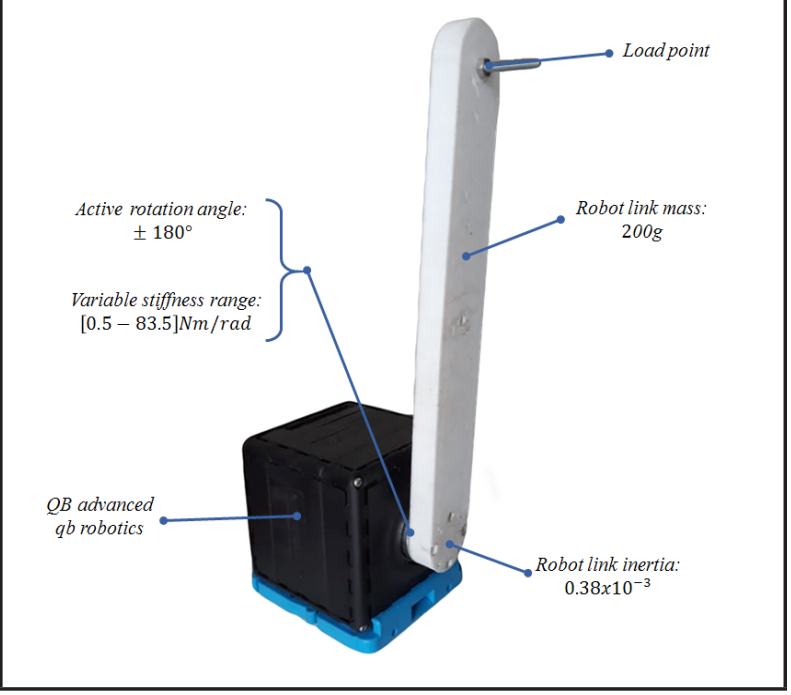

Based on (4), (5) and (6), the implementation algorithms are obtained in order to encode the tests that will be carried out.

$$
\begin{gathered}
\tilde{x}(T)=\left(G-K_{e} C\right) \tilde{x}(T-1)+H u(\mathrm{~T}-1)+K_{e} y(T-1) \\
v(T)=v(\mathrm{~T}-1)+y(T)+r \\
u(T)=K_{i} v(T)-K \tilde{x}(T)
\end{gathered}
$$

Where $v(T)$ is an auxiliary value that contains the input and output variables of the system; $r$ is the $T^{\text {th }}$ input vector, these equations are used to encode the control variables contained in the controlled system to be tested in an embedded system where $\tilde{x}(T)$ contains the present states calculated by the observer and $u(T)$ contains the present controller values where the control action is applied to the physical system. Additionally, for tests purposes, the used manipulator delivers the angular positions of the internal motors to the output, so the manufacturer provides an equation that allows to obtain the approximate stiffness $k$. This value is calculated from the internal motors angular positions as follows qb robotics $®$. (n.d.),

$$
k=k_{1} \cosh \left(a_{1}\left(\theta-q_{1}\right)\right)+k_{2} \cosh \left(a_{2}\left(\theta-q_{2}\right)\right)
$$

Where $q_{1}$ and $q_{2}$ are the angular positions of the internal motors and $k_{1}, k_{2}, a_{1}, a_{2}$ are scaling constants provided by the manufacturer.

The tests performed consist in the definition and tracking of cyclic trajectories, which are obtained from rehabilitation routines.

\section{Validation and Discussion}

In this section, the behavior of the system is validated through the execution of two tests that are commonly used in knee rehabilitation routines. The minimization of the dynamic effects is also verified by coupling the position $\mathrm{q}$ and the stiffness $\mathrm{k}$. We observe that the changes in one variable do not affect substantially the other variable due to the action of the implemented controller.

The tests consist of defining a desired reference position $\mathrm{q}$ as well a desired stiffness $\mathrm{k}$. The references are set considering the behavior of the leg when it is led to a certain position, then a sinusoidal reference is used to validate the dynamic behavior of the controlled system when a continuous routine is executed.

The step response of the system and the control signals are shown in Figure 4. The estimated states are shown in Figure 5. Observe that in Figure 4, the desired angular position is constant, as well as the desired stiffness. It is important to remark that the stiffness reference value is preset, which means that it will not follows exactly the desired reference, but its behavior depends on the stiffness calculation in (11). The angular position reaches the reference without error, in steadystate. During the transient of, small peaks appear due to the movement of. Physically, this behavior is normal due to the coupling. The controller is robust enough to bring and to the reference without suffering sudden changes. 
Figure 4. System Step response. Controlled Link Angular Position q and Stiffness Behavior
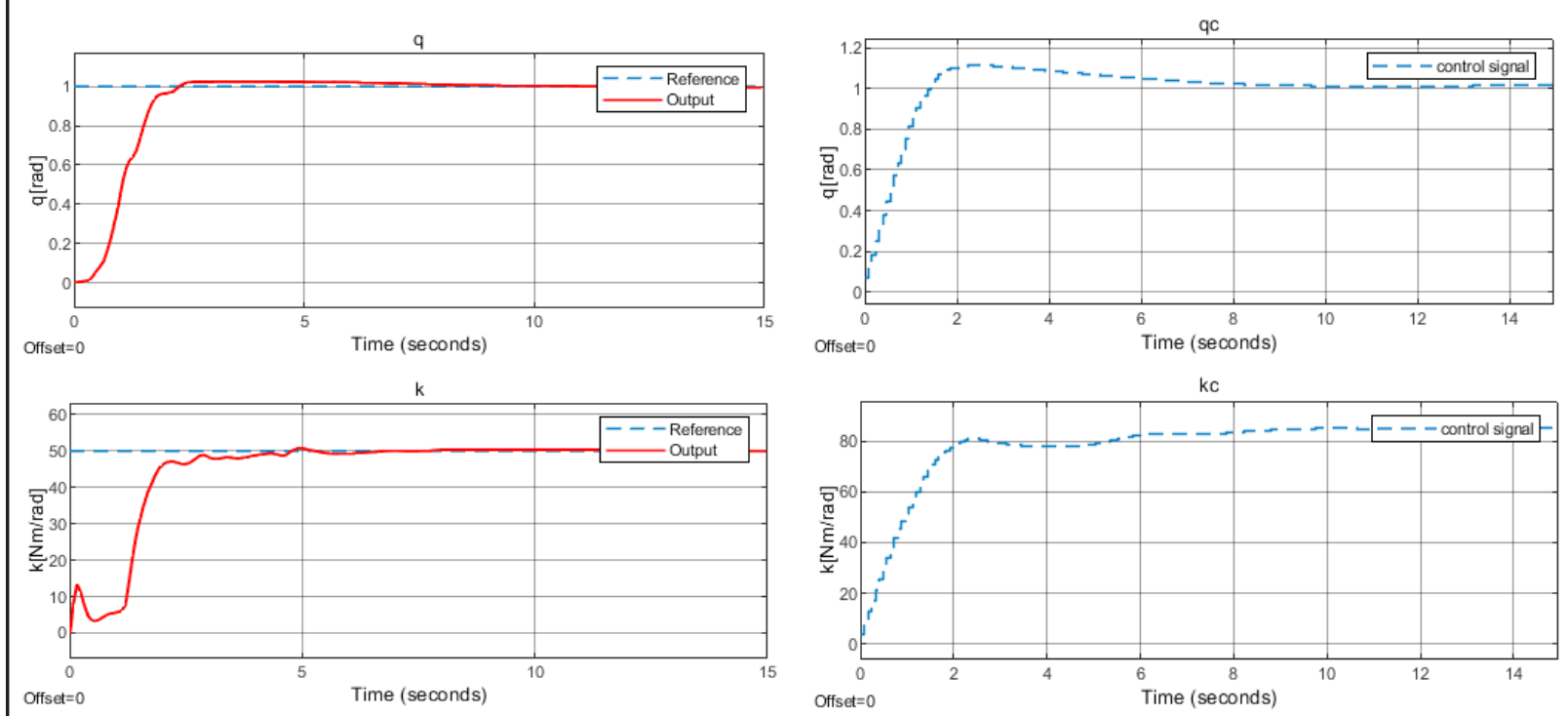

The estimated states in Figure 5 describe the behavior of the angular position, as well as the speed and acceleration. The estimated values are consistent with the physical behavior of the manipulator. Notice that the estimation values approach the real behavior for both $q$ and $k$.

Figure 5. Estimated States: Angular Position q and Stiffness $k$.

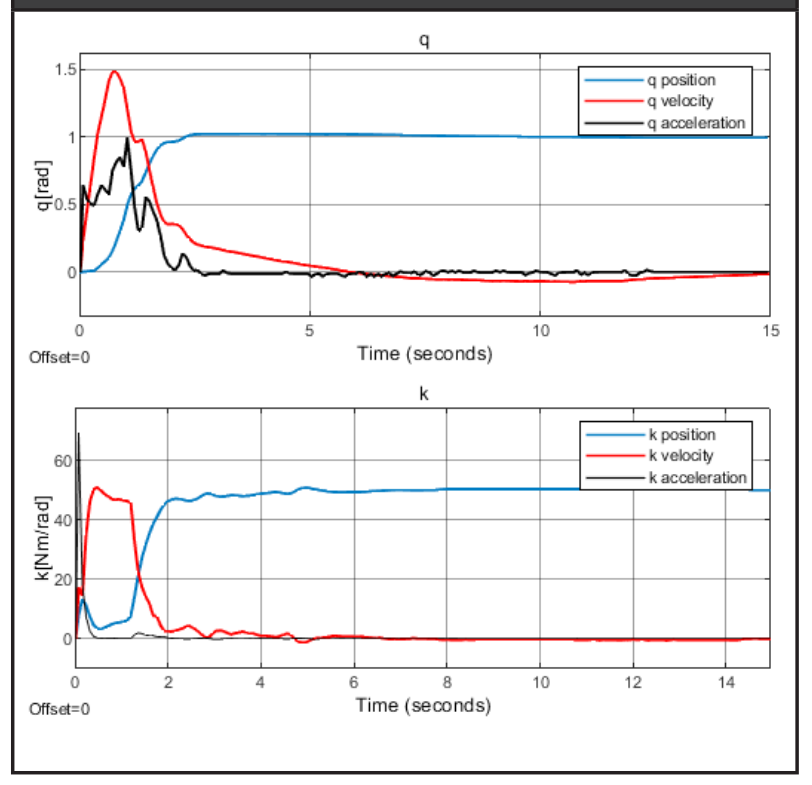

For the second test, we use a sinusoidal reference to validate dynamic behavior. Figure 6 shows the controlled system that follows the sinusoidal angular position profiles with zero steady-state error. In the case of the stiffness $k$, small oscillations occur at the highest effort. This behavior may be caused by the fatigue of the internal elastic components, which with the simultaneous movement of $q$ results in small vibrations that are physically unnoticeable due to an adequate control action. Figure 6 present also the control signals, where we show that the values of the control signals are consistent with the dynamic behavior of the output variables. It is evident that the control signals behavior is as expected.

The corresponding estimated states are presented in Figure 7. Notice that the angular velocity $\dot{q}$, presents oscillations when the stiffness increases rather than when it decreases. It should be emphasized that these are approximate values so that in the real system they are not noticeable when the movement occurs, over-oscillations and overshoots can be reduced with filters if required. 

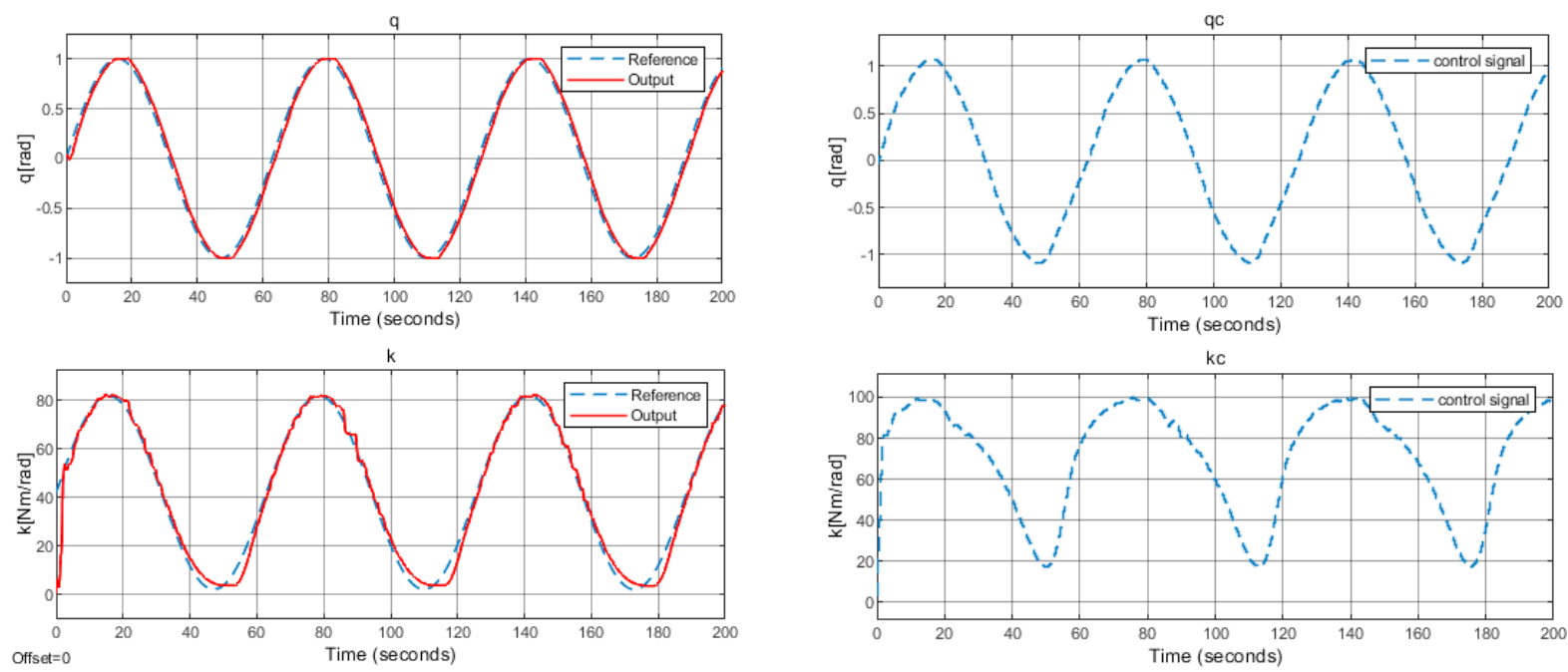

Figure 7. Step Response. Controlled Link Angular Position q and Stiffness Behavior
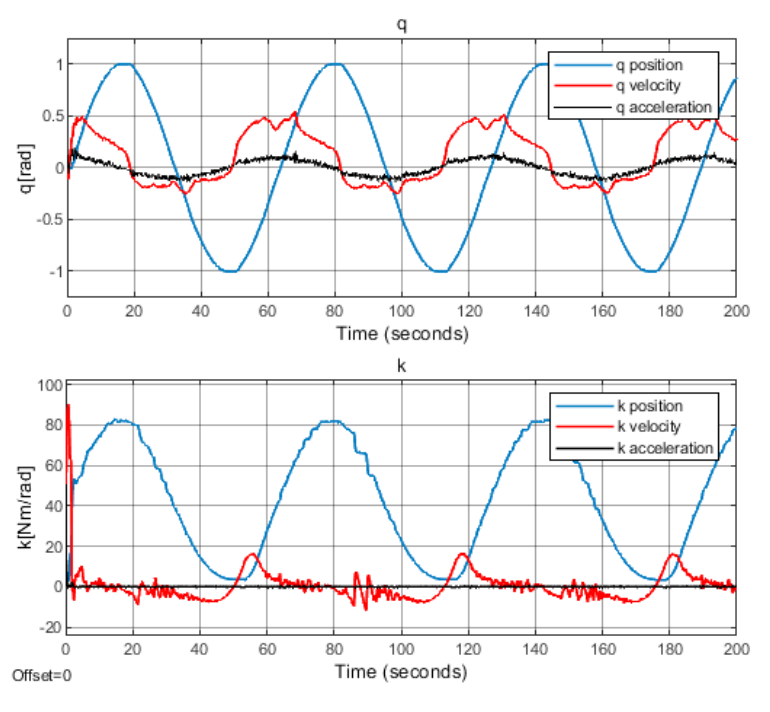

\section{Conclusions}

We have designed and implemented a dynamic feedback linearization control system for a soft actuated rehabilitation device, whose model has been simplified into a one-DoF system. The controller was designed to maintain the desired stiffness of the system and, in turn, carry out the rehabilitation routines previously defined by a physiotherapist. To estimate the stiffness of the

system, a state observer was used due to the complexity of the system, i.e. it is not possible to measure the stiffness directly.

The proposed control strategy guarantees smooth motions, but when there are sudden changes in the angular position, the joint becomes stiffer as expected, considering human natural motion, i.e. it resembles the knee joint. As mentioned, the controller allows changing the system stiffness by means of the torque adjustments made in the actuator. These changes do not affect the angular position control, allowing to follow the desired trajectories without error, and despite the existing coupling between the stiffness and the angular position controllers, it was demonstrated in simulation and in the physical manipulator the effectiveness of the controller and system stability, showing that the controlled system responds effectively to disturbances. The next step will be focused on the implementation of this control system on the dynamic model of the 5 -bar rehabilitation device already designed.

\section{Acknowledgments}

This work is funded by Universidad Militar Nueva Granada- Vicerrectoría de Investigaciones, under research grant for project IMP-ING-2291, entitled 'Diseño de un prototipo para rehabilitación de rodilla mediante el uso de actuadores flexibles'. 


\section{References}

Allen, M., Zhong, Q., Kirsch, N., Dani, A., Clark, W. W.\& Sharma, N. (2017), 'A nonlinear dynamics-based estimator for functional electrical stimulation: Preliminary results from lower-leg extension experiments', IEEE Trans-actions on Neural Systems and Rehabilitation Engineering25(12), 2365-2374.

Brahmi, B., Saad, M., Ochoa-Luna, C., Rahman, M. H.\& Brahmi, A. (2018), 'Adaptive tracking control of an exoskeleton robot with uncertain dynamics based on estimated time-delay control', IEEE/ASME Transactions onMechatronics23(2), 575-585.

Della-Santina, C., Bianchi, M., Grioli, G., Angelini, F., Catalano, M. G., Garabini, M. \& Bicchi, A. (2017), 'Controlling soft robots: Balancing feedback and feedforward elements', IEEE Robot. Automat. Mag.24(3), 75-83.URL: https:// doi.org/10.1109/MRA.2016.2636360.

Erwin, A. \& O’Malley, M. K. (2017), A novel exoskeleton for assessing passive wrist stiffness and active range of motion, in '2017 International Symposium on Wearable Robotics and Rehabilitation (WeRob)', pp. 1-1.

Expo, M.(n.d.), 'Rehabilitation exoskeletons', http://www. medicalexpo.es/fabricante-medical/exoesqueletorehabilitacion-10025.html. [Online; accessed 10-Aug2019].

Guatibonza, A., Solaque, L. \& Velasco, A. (2018), Kinematic and dynamic modeling of a 5-bar assistive device for knee rehabilitation, in 'Proceedings ETCM'.

Guo, S., Zhao, F., Wei, W., Guo, J., Zhao, X. \& Zhang, W. (2015), Soft actuator for hand rehabilitation, in '2015 IEEE International Conference on Mechatronics and Automation (ICMA)', pp. 2197-2202.

Htoon, Z. L., Sidek, S. N., Fatai, S. \& Rashid, M. M. (2016), Estimation of upper limb impedance parameters using recursive least square estimator, in '2016 International Conference on Computer and Communication Engineering (ICCCE)', pp. 144-148.

Huo, W., Mohammed, S., Moreno, J. C. \& Amirat, Y. (2016), 'Lower limb wearable robots for assistance and rehabilitation: A state of the art', IEEE Systems Journal10(3), 1068-1081.

Jujjavarapu, S. S. \& Esfahani, E. T. (2019), Improving stability in upper limb rehabilitation using variable stiffness, in '2019 41st Annual International Conference of the IEEE Engineering in Medicine and Biology Society (EMBC)', pp. 122-125.

Koller-Hodac, A., Leonardo, D., Walpen, S. \& Felder, D. (2010), A novel robotic device for knee rehabilitation improved physical therapy through automated process, in '2010 3rd IEEE RAS EMBS International Conference on Biomedical Robotics and Biomechatronics', pp. 820-824.

Lemerle, S., Fukushima, S., Saito, Y., Nozaki, T. \& Ohnishi, K. (2017), Wearable finger exoskeleton using flexible actuator for rehabilitation, in '2017 IEEE International Conference on Mechatronics (ICM)', pp. 244-249.

Lessard, S., Pansodtee, P., Robbins, A., Trombadore, J. M., Kurniawan, S. \& Teodorescu, M. (2018), 'A soft exosuit for flexible upper-extremity rehabilitation', IEEE Transactions on Neural Systems and Rehabilitation Engineering26(8), 1604-1617.

Luenberger, D. G. (1971), "an introduction to observers.", IEEE Transactions on Automatic Control. 16(6), pp. 596-602.

Luo, L., Peng, L., Hou, Z. \& Wang, W. (2017), An adaptive impedance controller for upper limb rehabilitation based on estimation of patients' stiffness, in '2017 IEEE International Conference on Robotics and Biomimetics (ROBIO)', pp. 532-537.

Ma, X., Yang, Q., Cai, J., Sun, M. \& Song, J. (2016), Design and research of 7 - dof upper-limb rehabilitation robot flexible joint, in '2016 International Conference on Advanced Robotics and Mechatronics (ICARM)', pp. 614-619.

National Institute of Biomedical Imaging, N.I. \& Bioengineering (n.d.), 'Ingeniería de Rehabilitación', https:// www.nibib.nih.gov/espanol/temas-cientificos/ ingenier\%C3\%ADa-de-rehabilitaci\%C3\%B3n. [Online; accessed 10-Aug-2019].

Ogata, K. (1996), Discrete Time Control Systems, PearsonEducation.URL: https://books.google.com.co/ books?id=aYFUs17m0YQC

Ogata, K. (2010), Modern Control Engineering, Pearson Education.

Parivash, F. \& Bamdad, M. (2015), Independent positionstiffness control for elbow rehabilitation robot with cable-based series elastic actuator, in '2015 22nd Iranian Conference on Biomedical Engineering (ICBME)', pp. 346-351.

Polytechnique fédérale de Lausanne, E. (n.d.), 'Soft actuator packs for human augmentation', https://www.epfl.ch/ labs/rrl/research-2/research-soft/page-148992-enhtml/. [Online; accessed 10-Aug-2019].

Qb robotics. (n.d.), 'Qbmove advanced', https://qbrobotics. com/products/qbmove-advanced/. [Online; accessed 06-Aug-2019].

Solaque, L. \& Velasco, A. (2019), Control strategy for a soft actuated knee rehabilitation device, in 'Proceedings of ICMRE'. 
Umivale, P. S. (2011), 'Patología de la rodilla: Guía de manejo clínico'.

Wu, Q., Wang, X., Chen, B. \& Wu, H. (2018), 'Design and fuzzy sliding mode admittance control of a soft wear-able exoskeleton for elbow rehabilitation', IEEE Access 6, 60249-60263.

Guatibonza Artunduaga, A.F.; Solaque Guzmán, L.E.; Velasco Vivas, A. (2020). Dynamic Feedback Control And State Observers For A Knee Rehabilitation Device Using Soft Action. Revista EIA, 17(33) enero-junio, Reia33013, pág. 1-10. Disponible en: https://doi.org/10.24050/reia. v17i33.1363 